\title{
Asymmetric Hunting And Chaotic Motion Of Railroad Vehicles
}

True, Hans

Published in:

Proceedings of the ASME/IEEE Spring Joint Railroad Conference

Publication date:

1992

Document Version

Publisher's PDF, also known as Version of record

Link back to DTU Orbit

Citation (APA):

True, H. (1992). Asymmetric Hunting And Chaotic Motion Of Railroad Vehicles. In Proceedings of the ASME/IEEE Spring Joint Railroad Conference (pp. 35-40). IEEE.

\section{General rights}

Copyright and moral rights for the publications made accessible in the public portal are retained by the authors and/or other copyright owners and it is a condition of accessing publications that users recognise and abide by the legal requirements associated with these rights.

- Users may download and print one copy of any publication from the public portal for the purpose of private study or research.

- You may not further distribute the material or use it for any profit-making activity or commercial gain

- You may freely distribute the URL identifying the publication in the public portal

If you believe that this document breaches copyright please contact us providing details, and we will remove access to the work immediately and investigate your claim. 
ASYMMETRIC HUNTING AND CHAOTIC MOTION OF RAILROAD VEHICLES

\author{
Dr. Hans True \\ Dept. of Applied Mathematical Physics \\ The Technical University of Denmark \\ DK-2800 LYNGBY \\ Denmark
}

ABSTRACT

In this paper evidence is compiled to demonstrate that asymmetric hunting of railway vehicles and chaotic motion occur as a consequence of the instabilities of the vehicle above certain critical speeds. References are made both to theoretical investigations of mathematical models and to a scale-model roller rig experiment. These instabilites may be a cause for the uneven wear of wheels which has been observed on some unit trains running always between the same two destinations over the same line.

\section{INTRODUCTION}

Recent investigations of hunting show, that there exist various kinds of hunting motion. It is often the case - as is tacitly assumed - that the wheelset or the truck will oscillate periodically around the track centerline after the onset of hunting. The assumption is based on the symmetries of the wheel and the track respectively.

In spite of these symmetries the wheelset may oscillate periodically around an off-centered line parallel to the track. In that case there exist two equally probable oscillation modes; one is the reflection of the other in the track center line. It will depend on the disturbances in the track geometry, which of the two possibilities the wheelset or bogie will choose. after the speed of the vehicle has passed a certain critical speed. Each of the two asymmetric modes is very stable, so it may need a large disturbance or a change in the direction of the track to "knock" the asymmetric oscillation out of its mode.

Another situation occurs, when the hunting amplitude leads to flange contact at one or both rails. Theoretica1 investigations have demonstrated, that the oscillations often have an erratic appearance. A closer investigation of these oscillations then have revealed the existence of chaos.

All results so far indicate that chaos is no more dangerous than a periodic oscillation. The plotted time series look like strong periodic oscillations with smal1 erratic disturbances superposed. What is very important, however, is that chaotic wheelset or bogie oscillations have been found often to be asymmetric. Either the oscillations are purely asymmetric or the oscillations jump back and forth between two asymmetric modes in an erratic fashion. Symmetric chaotic motion may occur at low speeds.

Although the bias in the yaw is very small, it may have a measurable effect on trains running back and forth over the same line under conditions, which change only little from time to time. Once the wheels of a wheelset undergo different wear as a consequence of a bias in yaw, the effect is selfamplifying. The bias in yaw will be more pronounced, which leads to a growing differential wear and so on.

In this article we present results from investigations of a mathematical model of the motion of first a single wheelset and next of a truck. In all models it is assumed the motion is with constant speed $V$ along an ideal, rigid, straight and horizontal track. The speed $V$ is the control parameter in the problems. All displacements are measured in a coordinate frame, which moves along the track centerline with the speed $V$.

\section{THE WHEELSETS}

Knudsen et al. (1992) investigated a model of a wheelset suspended in a frame. The frame can rotate around a frictionless, vertical pivot in the car floor. It is assumed that the vertical displacements are smali, so they only need to consider two degrees of freedom: Lateral and yaw motion. Only the lateral motion is restricted by linear springs without damping. The model is shown on figure 1.

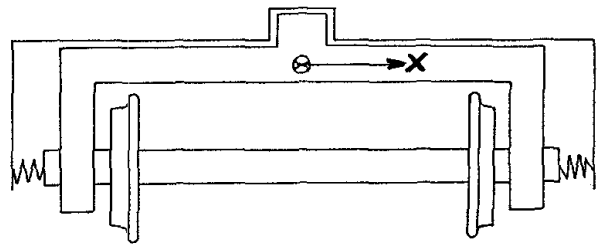

Figure 1 Arrangement of the wheelset with moving coordinate system. 
The wheel profile is conical, and the rail surfaces are approximated by arcs of a circle. Apart from the springs all parts are assumed to be perfectly rigid. The creep forces are determined by Vermeulen and Johnson's (1964) theory. The flange force is approximated by a very stiff linear spring with a dead band. Gravitational stiffness is ignored. The mathematical formulation of the problem as a system of four ordinary, first order differential equations is presented in (Knudsen et al. 1992). Table 1 presents some of the parameter values used.

Table 1.

\begin{tabular}{cll}
\hline constant & value & description \\
\hline $\mathrm{m}$ & $1022 \mathrm{~kg}$ & mass of wheelset \\
$\mathrm{I}$ & $678 \mathrm{kgm}$ & moment of inertia \\
$\mathrm{a}$ & $0.716 \mathrm{~m}$ & half of track gauge \\
$\delta$ & $9.1 \mathrm{~mm}$ & dead band \\
$\mathrm{k}_{1}$ & $1.823 \times 10^{4} \mathrm{Nm}^{-1}$ & lateral spring constant \\
$\mathrm{k}_{0}$ & $14.60 \mathrm{MNm}^{-1}$ & "flange spring" constant \\
$\mathrm{r}_{0}$ & $0.4572 \mathrm{~m}$ & centered wheel rolling radius \\
$\lambda$ & 0.05 & slope of wheel profile \\
$\mu$ & 0.15 & coefficient of friction \\
$\mu \mathrm{N}$ & $10 \mathrm{kN}$ & N is the vertical force \\
& & between wheel and rail.
\end{tabular}

Jaschinski (1990) and Knudsen et al. (1991) consider a dicone suspended in a moving frame by longitudinal and lateral springs in the outer ends of the dicone. The flange forces are ignored. It is considered as a simple model of a real wheelset on rails. It still has most of the basic properties of the real wheelset on rails since the creepage-creep force relations are assumed to be nonlinear. The creep forces in the model depend not only on the creepages but also on the constraint forces. The model has three degrees of freedom: Lateral, yaw and roll motion. For the calculation of the creep forces they use an approximation of Kalker's creep force laws for small creepages with a constant saturation value for large creepages. The equations of motion and their derivation are presented in (Jaschinski, 1990). Jaschinski also made experiments with his dicone on a small roller rig. In Table 2 some of the parameter values used are shown

Table 2. (from Jaschinski, 1990 p. 138)

\begin{tabular}{|c|c|c|}
\hline constant & value & description \\
\hline m & $16.08 \mathrm{~kg}$ & mass of the dicone \\
\hline I & $0.366 \mathrm{kgm}^{2}$ & moment of inertia \\
\hline a & $0.1506 \mathrm{~m}$ & $\begin{array}{l}\text { half distance of nominal rol- } \\
\text { ling radii }\end{array}$ \\
\hline $\mathrm{k}_{1} \mathrm{k}_{2}$ & $10^{4}-10^{5} \mathrm{Nm}^{-1}$ & variable spring constants \\
\hline $\begin{array}{l}\mathbf{r}_{0} \\
\lambda\end{array}$ & $\begin{array}{l}0.1 \mathrm{~m} \\
0.0262 \mathrm{rad}\end{array}$ & $\begin{array}{l}\text { centered cone rolling radius } \\
\text { cone angle }\end{array}$ \\
\hline$\mu$ & 0.12 & coefficient of friction \\
\hline $\mathrm{N}$ & $78.87 \mathrm{~N}$ & $\begin{array}{l}\text { normal force in contact point } \\
\text { for the nominal position of } \\
\text { the dicone. }\end{array}$ \\
\hline
\end{tabular}

Meijaard (1991) also investigates the dynamics of a suspended wheelset theoretically. His model has two degrees of freedom (lateral and yaw motion), and the differential equations are nondimensionalized through a proper scaling. His creep force calculations are based on linear Kalker theory, and the flange forces are modelled by a partially elastic impact involving a coefficient of restitution. The wheelset is suspended by linear lateral and yaw springs in a frame.
THE TRUCKS

True (1992) has examined Cooperrider's (1972) truck mode1. It consists of two of the wheelsets Knudsen et al. (1992) examined, suspended in a stiff frame. In addition to the lateral springs both longitudinal and vertical springs are added in the primary suspension. A secondary suspension system connects the frame with the car body. Figure 2 shows the model of the truck. The $\otimes V$
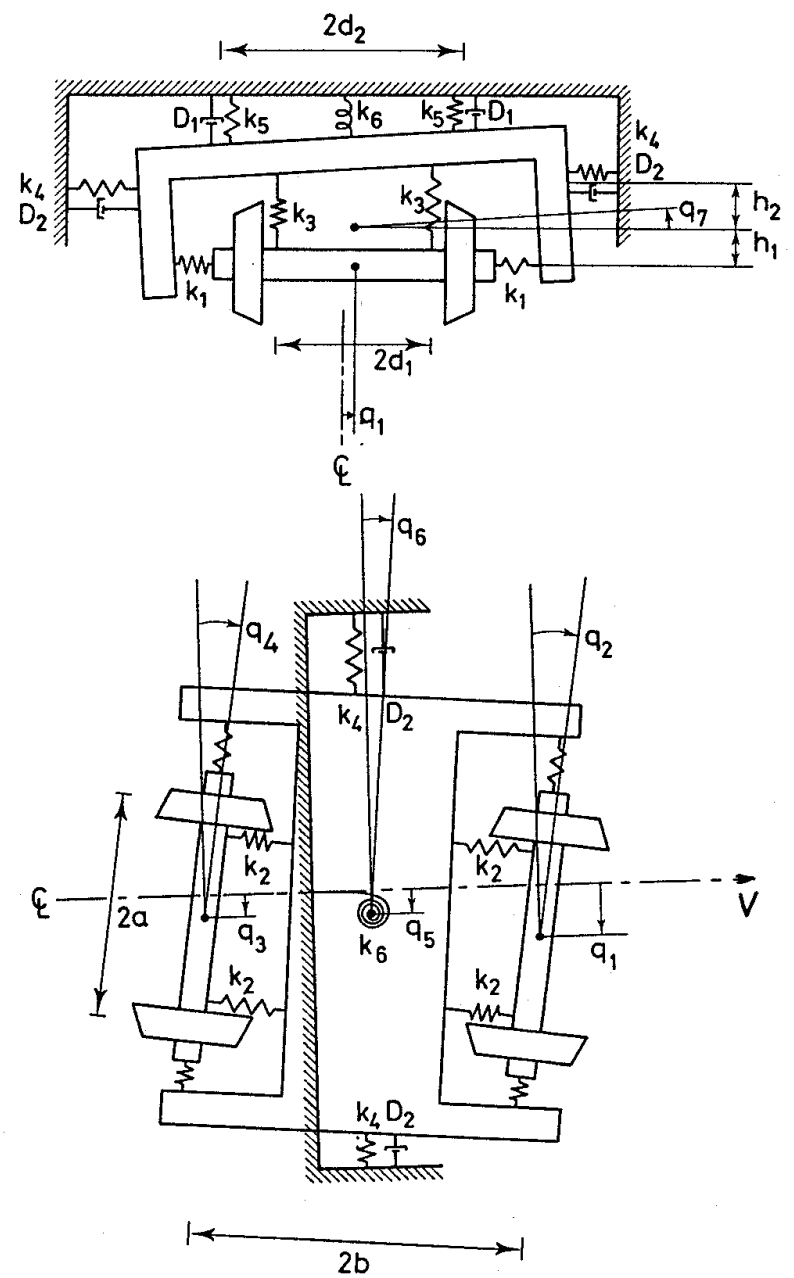

Figure 2 Bogie model with the notation used.

values of the additional parameters are given in (True, 1992). The model has seven degrees of freedom: Lateral and yaw for each of the wheelsets and truck frame and also roll of the truck.

Jaschinski (1990) also examined a truck model. It is made in scale $1: 5$, and it consists of a truck frame and two conical wheelsets without flanges. The primary suspension consists of longitudinal, lateral ad vertical spring without dampers. The frame is fixed only longitudinally by a spring on either side, and it can move freely in the lateral and yaw direction. 
All the theoretical results were obtained through numerical integration of the system of equations of motion. Knudsen et al. (1992) use either the LSODA routine, which automatically switches between stiff and non-stiff solution methods whenever needed or an eighthstage explicit Runge-Kutta pair of order five and six. It uses variable time step and error control. True (1992) uses the LSODA routine in connection with the continuation or path following routine PATH. PATH determines the solutions with a relative error of $10^{-9}$.

Knudsen et al. (1991) use specially in-house developed software and the earlier mentioned software package PATH. Jaschinski (1990) uses a routine DASSL, which provides the solution of the system of differential equations and the algebraic constraint equations simultaneously (Brenan et al. 1989).

Finally Meijaard (1991) uses a classical fourthorder Runge-Kutta method with a fixed stepsize. Since the dynamical system has isolated discontinuities, the integration is restarted at the points of discontinuity - possibly with an adjusted initial value.

Table 3. (from Jaschinski, 1990 p. 70-72)

\begin{tabular}{cll}
\hline constant & value & description \\
\hline $\mathrm{m}_{\mathrm{F}}$ & $42.82 \mathrm{~kg}$ & mass of frame \\
$\mathrm{m}$ & $16.08 \mathrm{~kg}$ & mass of one wheelset \\
$\mathrm{I}_{\mathrm{FX}}$ & $0.769 \mathrm{kgm}$ & moments of inertia \\
$\mathrm{I}_{\mathrm{FY}}$ & $0.921 \mathrm{kgm}^{2}$ & for the frame \\
$\mathrm{I}_{\mathrm{FZ}}$ & $1.573 \mathrm{kgm}^{2}$ & \\
$\mathrm{I}_{\mathrm{X}}=\mathrm{I}_{\mathrm{Z}}$ & $0.366 \mathrm{kgm}^{2}$ & moments of inertia \\
$\mathrm{I}_{\mathrm{y}}$ & $0.0605 \mathrm{kgm}^{2}$ & for the wheelsets \\
$\mathrm{c}_{\mathrm{y}}^{\mathrm{c}}$ & $6.4 \cdot 10^{4} \mathrm{~N} / \mathrm{m}$ & stiffness of primary springs \\
$\mathrm{c}_{\mathrm{x}}^{\mathrm{y}} \mathrm{y}$ & $2.5 \cdot 10^{5} \mathrm{~N} / \mathrm{m}$ & stiffness of secondary \\
& & springs \\
$\mathrm{c}_{\mathrm{z}}$ & $5.0 \cdot 10^{5} \mathrm{Nm}$ & \\
$\lambda^{\mathrm{z}}$. & $0.0262 \mathrm{rad}$ & cone angle \\
$\mathrm{r}_{0}$ & $?$ & centered rolling radius
\end{tabular}

RESULTS, WHEELSETS

Knudsen et a1. (1992) found, that their wheelset model has one asymptotically stable solution for the speed $V$ less than $10.050 \mathrm{~m} / \mathrm{s}$. The solution describes a steady, centered motion along the track. At the critical speed $\mathrm{V}=10.050 \mathrm{~m} / \mathrm{s}$ the solution loses it stability, and a limit cycle grows up with the speed. Already at $\mathrm{V}=10.056 \mathrm{~m} / \mathrm{s}$ flange contact occurs. The "amplitude" of the motion then grows much slower, and the ampli-. tude is no longer well defined. It lies within a band, which widens with growing speed. The phenomenon can be illustrated on a socalled bifurcation diagram, figure 3 , where the positive maximum of the lateral displacement of the wheelset is plotted against the speed V.

The broad band of oscillation maxima for one and the same speed V indicates, that the oscillation is no longer periodic. Knudsen et al. (1992) verify in their paper, that the motion is chaotic, but it is obvious from Eigure 4 that the chaotic deviations from the periodic motion hardly will be visible in a time series such as figure 4, where the lateral displacement is shown versus time.

The structure of figure 3 with narrowing bands in certain speed ranges is typical of chaotic behavior. Around $\mathrm{V}=10.31 \mathrm{~m} / \mathrm{s}$ the chaos concentrates onto four narrow bands. They represent two asymmetric solutions with double period. These modes go through a frequency doubling at $\mathrm{V}=10.32 \mathrm{~m} / \mathrm{s}$, and then the wheelset will oscillate in one of two different asymmetric modes up to $\mathrm{V}=10.59 \mathrm{~m} / \mathrm{s}$. Please remember that on $1 \mathrm{y}$ the positive

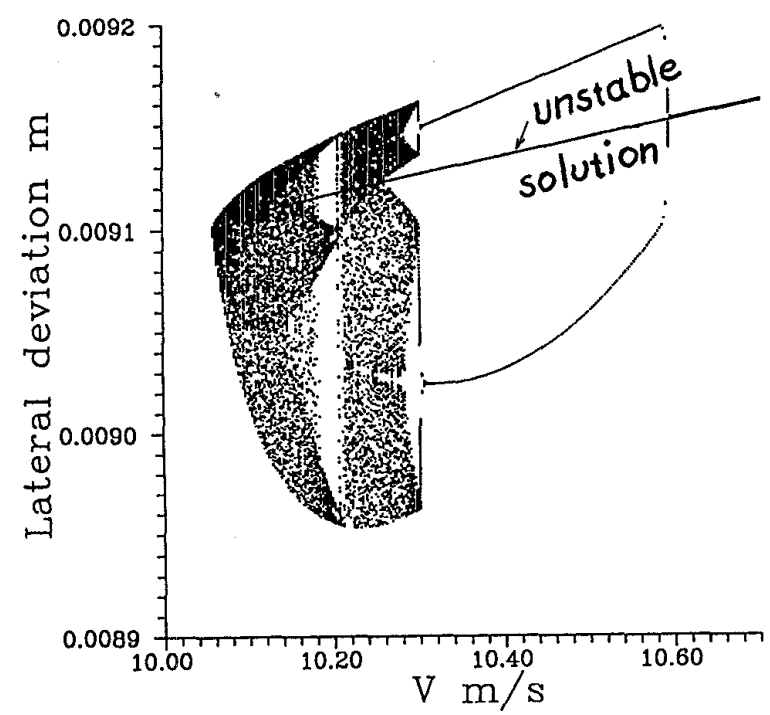

Figure 3 Maximum lateral displacement versus time. For $10.056 \mathrm{~m} / \mathrm{s}<\mathrm{V}<10.31 \mathrm{~m} / \mathrm{s}$ the wheelset moves chaotically, and for $10.32 \mathrm{~m} / \mathrm{s}<\mathrm{V}<10.59 \mathrm{~m} / \mathrm{s}$ the wheelset oscillates in one of two different asymmetric modes.

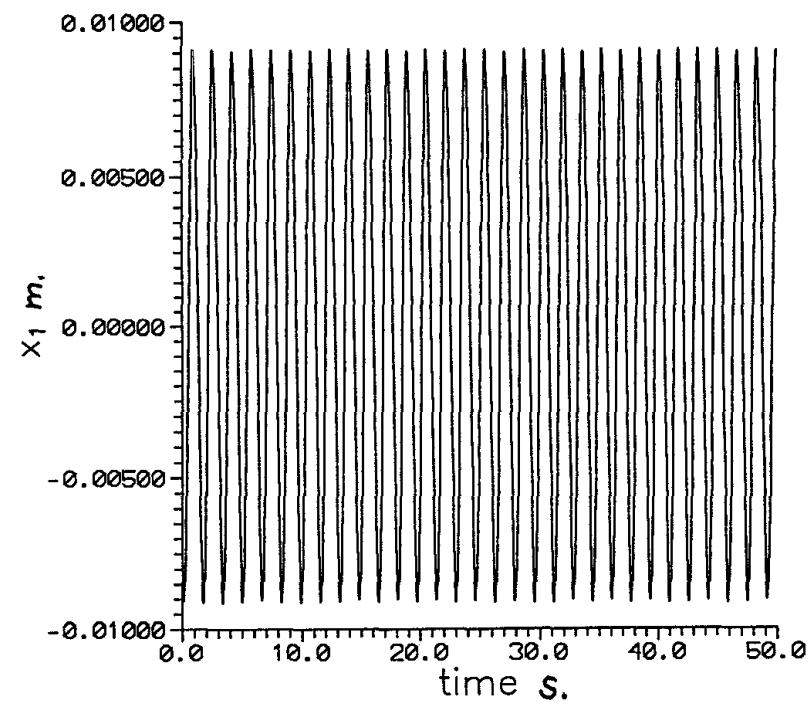

Figure 4 Lateral displacement versus time. $V=10.1$ $\mathrm{m} / \mathrm{s}$. Chaotic motion.

maxima of the two oscillations are shown. The upper branch of the plot on figure 3 thus corresponds to the mode, which has a bias towards the right rail. The lower branch corresponds to the mode, which has a bias towards the left rail. The branch in the middle corresponds to an unstable, symmetric oscillation, which will never be observed except as part of a transient below $\mathrm{V}=10.59$ $\mathrm{m} / \mathrm{s}$. At $\mathrm{V}=10.59 \mathrm{~m} / \mathrm{s}$ the symmetric oscillation becomes stable, and the two asymmetric modes cease to exist. 
Knudsen et al extend their investigations to $V \sim 50$ $\mathrm{m} / \mathrm{s}$, and they find no further speed ranges with symmetric limit cycles. All the stable oscillations are either chaotic or asymmetric limit cycles.

Meijaard's (1991) independent investigation supports the qualitative picture outlined above. His results can be summarized in the following way: For $V<1$ (nondimensional speed) the trivial solution (all displacements equal to zero) is asymptotically stable. For $1.0<V<1.165$ the wheelset moves chaotica11y. In the range $1.165<\mathrm{V}<1.318$ two asymmetric limit cycles exist. A new phenomenon exists in the range $1.318<\mathrm{V}<$ 1.679 where the two asymmetric Iimit cycles coexist with a symmetric limit cycle. If means, that in reality three different modes of oscillation may be observed. It will depend on the disturbances which one of the three modes that will be seen in experimental test. Above $V=1.679$ the symetric oscillation is the only stable solution - at least up to $V=2.0 \mathrm{~m} / \mathrm{s}$, where the calculations stop.

Knudsen et a1. (1991) find that their wheelset model has a stationary equilibrium solution - the trivial solution - which is asymptotically stable up to $\mathrm{V}=15.69 \mathrm{~m} / \mathrm{s}$. At that speed an unstable periodic oscillation develops with an amplitude which grows with decreasing speed. At $V=11.9 \mathrm{~m} / \mathrm{s}$ the unstable solution is annihilvated in a coalescence with a stable periodic solution, which exists only above $V=11.9 \mathrm{~m} / \mathrm{s}$. This gives rise to a hysteresis phenomenon that is wellknown from road tests. The vehicle runs steadily up to a certain speed $V_{U}$, where it suddenly changes into a measurable hunting oscillation. When the vehicle slows down, the hunting persists until a lower critical speed $V_{L}$ is reached, where the hunting suddenly stops. In the speed range $V_{L}<V<V_{U}$ there exist two stable modes: The stationary solution with no hunting and a hunting mode. The critical velocity $V_{U}$ is sensitive to external disturbances and may often be difficult to measure accurately in field experiments. In such cases the change from stationary to hunting motion is sensitive to disturbances and takes place before the speed $V_{U}$ is reached. The larger the disturbance the smaller the speed at which the transition occurs.

At the speed $V=12.25 \mathrm{~m} / \mathrm{s}$ the symmetric limit cycle loses stability, and two asymmetric limit cycles develop. An overall picture of the transitions is presented on figure 5 and the two asymmetric limit cycles are shown on figure 6 . When the speed is increased further, the asymmetric limit cycles lose stability and the motion becomes chaotic through a cascade of period doublings. This transition is a wellknown feature in nonlinear dynamics. Also in this case the amplitude of the chaos is so small that it is unlikely that it will be detected in a field test. The chaos disappears in a reverse period doubling cascade ending at $\mathrm{V}=12.56 \mathrm{~m} / \mathrm{s}$ where two stable asymmetric limit cycles develop. At $12.57 \mathrm{~m} / \mathrm{s}$ the original symmetric limit cycle regains its stability. At higher speeds other transitions occur, and the interested reader is referred to Knudsen et a1. (1991).

\section{RESULTS, TRUCKS}

True's (1992) results are shown on figures 7 and 8. The truck model has a stationary solution, which is asymptotically. stable up to $V=65.4 \mathrm{~m} / \mathrm{s}$. A periodic oscillation starts at $\mathrm{V}=65.4 \mathrm{~m} / \mathrm{s}$, its amplitude grows with decreasing speed, and it is unstable. At $V=63.6$ $\mathrm{m} / \mathrm{s}$ flange contact occurs, and a stable, symmetric limit cycle develops. Its amplitude grows with the speed until around $113 \mathrm{~m} / \mathrm{s}$. A detailed picture of the stable and unstable solutions around $\mathrm{V}=110 \mathrm{~m} / \mathrm{s}$ is shown on figure

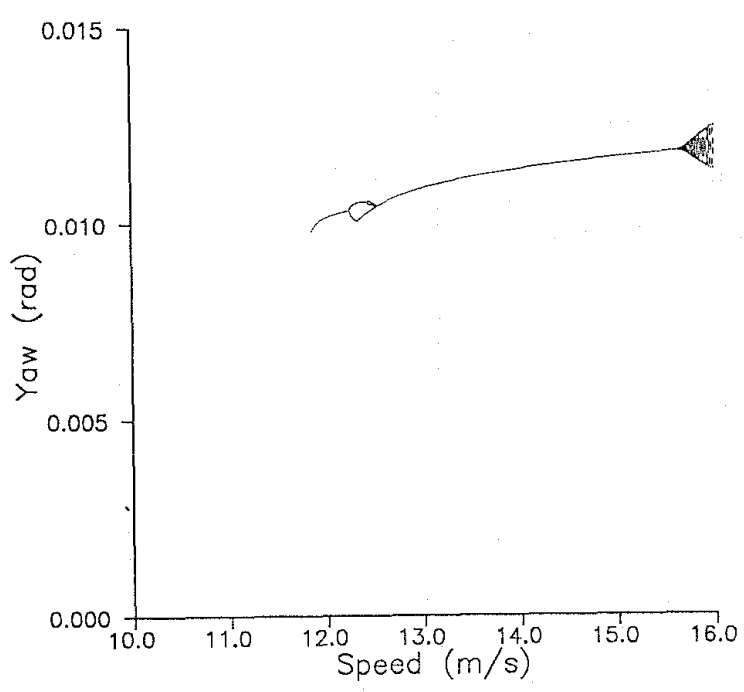

Figure 5 Maximum yaw angle versus speed from Knudsen et a1. (1991).

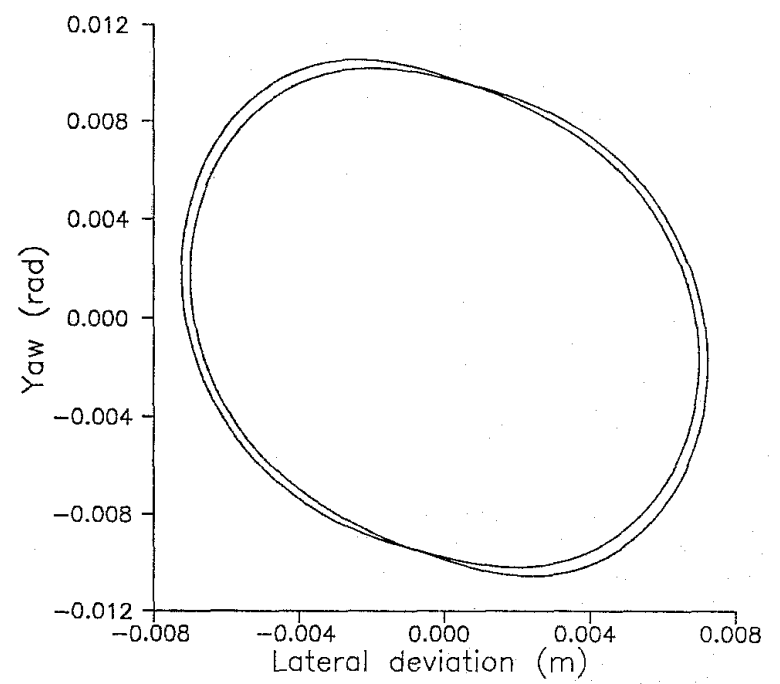

Figure 6 Projection of the two asymmetric limit cycles at $12.45 \mathrm{~m} / \mathrm{s}$ onto the plane of lateral and yaw-displacements. From Knudsen et a1. (1991).

8. In addition to the solutions, indicated on the figure, asymmetric chaotic solutions were found around $V=113 \mathrm{~m} / \mathrm{s}$. An evidence hereof is presented on figure 9. In the projection shown a limit cycle would have been a closed curve. The width of the band shown is a demonstration of the erratic nature of the motion, and it corresponds to the band of positive maxima shown on figure 3 in the preceding section. Notice that the phase plot extends from the lower left hand corner to the upper right hand corner with the extremal values close 


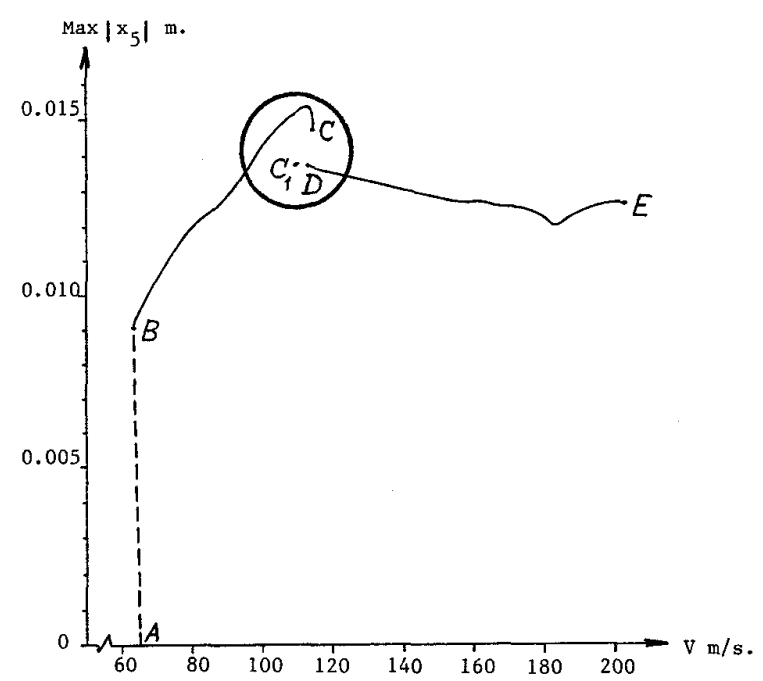

Figure 7 Amplitude of the lateral displacement of the rear axle versus speed.

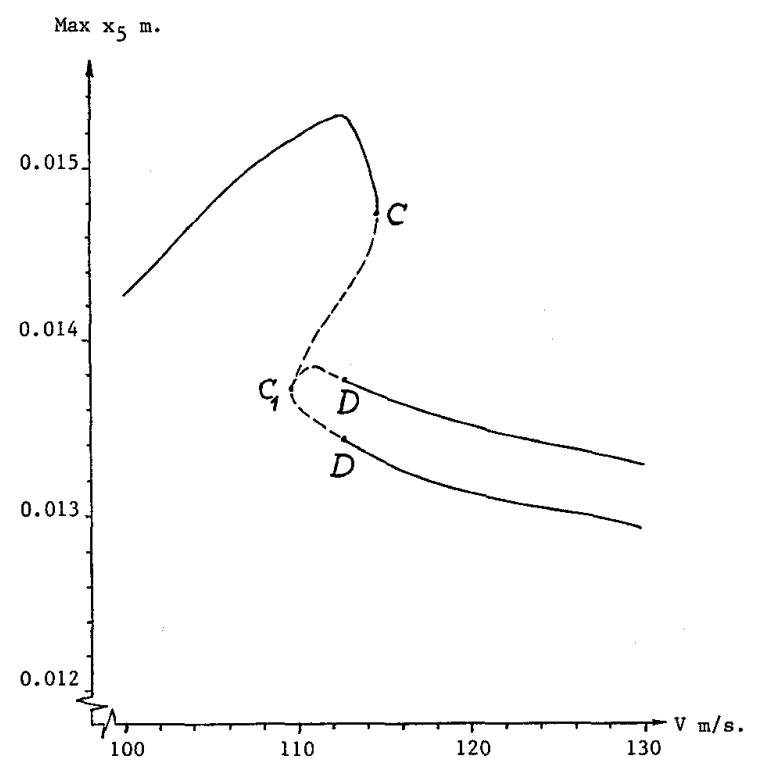

Figure 8 A blow up of the circular domain on fig. 7 . The figure shows the maximum positive lateral displacement of the rear axle versus speed.

to the $45^{\circ}$ line. It demonstrates that both axles in the bogie have a bias towards the same rail. At $\mathrm{V}=112.7$ $\mathrm{m} / \mathrm{s}$ two stable asymmetric oscillations develop, which continue to exist up to a very high speed. The distance between the neutral lines of the two different oscillations is measured in tenths of a millimeter and is therefore undetectable in field experiments. True (1992) calls these oscillations periodic, but recent

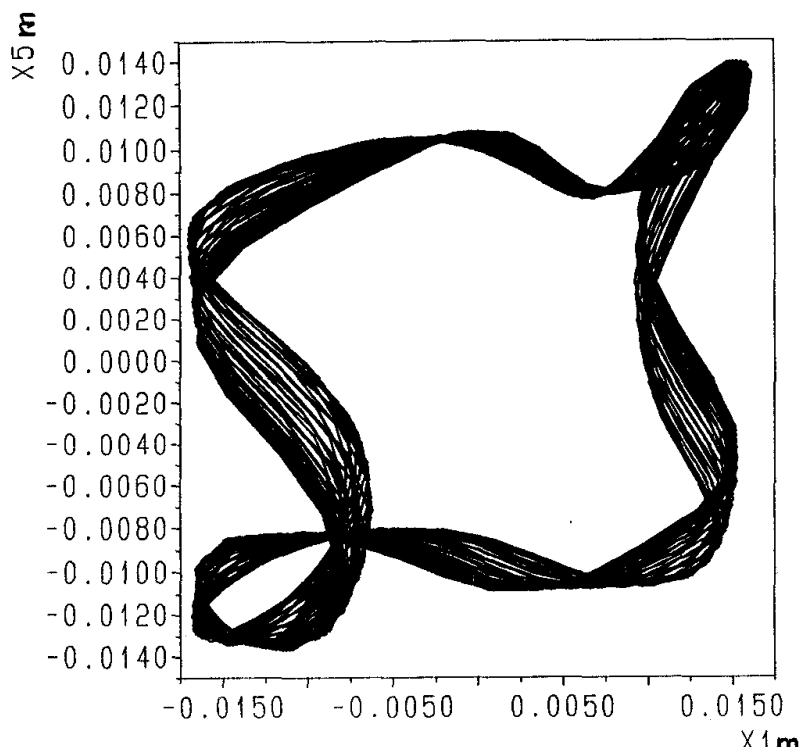

Figure 9 A projection of the phase space trajectories at $\mathrm{V}=112.9 \mathrm{~m} / \mathrm{s}$ onto the $\mathrm{X} 1-\mathrm{X} 5 \mathrm{plane}, \mathrm{X} 1$ and $\mathrm{X} 5$ are the lateral displacements of the front and rear axle respective1y. Chaotic behavior.

investigations indicate, that the oscillations may be weakly quasi-periodic. Figure 10 shows the lateral

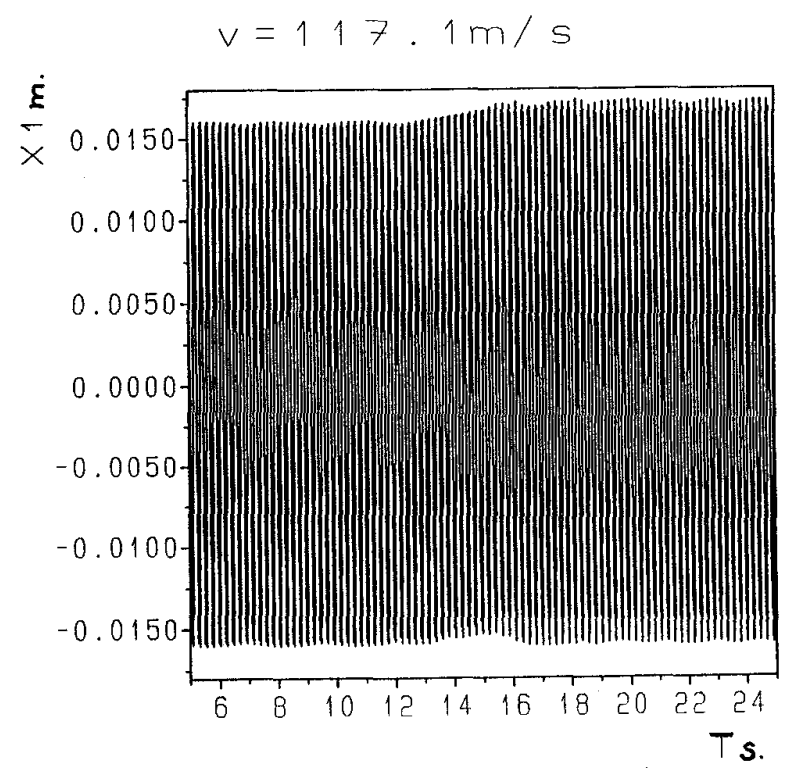

Figure 10 Transient behavior of the lateral displacement of the front axle at $\mathrm{V}=117.1 \mathrm{~m} / \mathrm{s}$. The initial conditions are on the unstable symmetric solution. Around $\mathrm{T}=15 \mathrm{~s}$. the oscillation becomes asymmetric. 
displacement of the front axle versus time. The integration starts with initial conditions on the unstable symmetric solution, and it is seen that the amplitude grows slowly over approximately 15 seconds. Then the motion changes to one of the stable asymmetric oscillations. An amplitude modulation is visible on the figure, and it may be due to quasi-periodicity. Further investigations are necessary to determine the true nature of these oscillations.

Jaschinski's (1990) numerical and experimental results show the same tendency. He makes a comparison between the numerical simulation and the experimental results and finds good agreement. Jaschinski finds two asymmetric limit cycles for his truck running between $11 \mathrm{~m} / \mathrm{s}$ and $14 \mathrm{~m} / \mathrm{s}$. This was the highest speed the experiment would allow, because the amplitude of the oscillations of the flangeless wheels lead to "derailing" above that speed. At a speed of $13 \mathrm{~m} / \mathrm{s}$ the calculated $(11 \mathrm{~mm})$ and measured $(11,5 \mathrm{~mm})$ amplitudes of the front wheelset are in very good agreement. For the rear wheelset the calculated values $(16 \mathrm{~mm}$ ) are somewhat larger than the measured values of about $13 \mathrm{~mm}$. Jaschinski writes that the difference may be due to the neglect of the particular kinematics of the roller rig in the equations of motion. The results also show that both wheelsets have the same bias, and the neutral lines of the two different asymetric limit cycles are $3 \mathrm{~mm}$ apart. This distance grows with the speed. Taking into account that he considers a scaled down model, the asymmetry is large. Jaschinski ascribes the asymmetric behavior to the low ratio of the lateral over longitudinal frame suspension stiffness. In his model the ratio is equal to 0.2 . This ratio is certainly important, but it can not be the single determining quantity. In Trues (1992) truck model the corresponding ratio of lateral over longitudinal frame suspension is around $7 \cdot 10^{-4}$, and the distance between his neutral lines of oscillation is measured in tenths of a millimeter.

\section{CONCLUSION}

The evidence collected in this paper shows that asymmetric hunting may be even more common in reality than symmetric hunting. Furthermore chaotic behavior can be expected under certain circumstances, and finally it is demonstrated that a railroad vehicle may behave in more than one way under the same external. conditions (existence of multiple solutions (attractors)).

Although the bias in the asymmetric hunting motion is of small magnitude, it may lead to lopsided wear of wheelsets. The lopsided wear is self-amplifying, because it leads to a decrease of the speed at which hunting starts, and the asymmetry thus created is biased in the same direction as the instability on the track section where the asymetric motion started. Even in the cases where the asymmetry is of small magnitude, it may have an observable effect on trainsets that run exclusively on a certain railroad line (suburban trains, subways, unit trains for coal or ore). A vehicle that runs all over the system will be exposed to disturbances that will act first in one and then maybe in the other direction, so on the average both wheels on a wheelset will be worn evenly. Therefore uneven wear caused by a hunting instability should not be observed very often.

The erratic or chaotic behavior presented here is of small magnitude relative to the amplitude of the periodic motion on which it is superposed. It presents no danger to railroad operations. However large amplitude chaotic and asymnetric motion has been found in theoretical investigations (Kaas-Petersen 1986) at speeds that are unrealistic today. However chaotic behavior depends strongly on the truck design, and investigations of other truck models have been started to detexmine whether they move chaotically with large bias at realistic speeds. The kind of chaos presented here may only lead to difficulties in finding the hunting motion in theoretical investigations of railway dynamical problems.

Finally attention must be given to multiple soIutions. In numerical simulations the result depends on the initial conditions. If multiple solutions exist, there may be a disagreement between the simulations and the experimental results - simply due to difference in the initial conditions. When theoretical investigations are made," it is therefore important to know all the stable solutions for a given speed whenever there exist more than one stable solution.

This work was supported by the Danish Council for Scientific and Industrial Research grant no. 16-4786.M.

\section{REFERENCES}

Brenan, K.E., Campbe11, S.L., and Petzold, L.R., 1989, Numerical Solution of Initial-Value Problems in Differential-Algebraic Equations, North-Holland, New York, Amsterdam, London.

Jaschinski, A., 1990, "On the Application of Similarity Laws to a Scaled Railway Bogie Mode1", Doctora1 Thesis, Technische Universiteit Delft, The Netherlands. Kaas-Petersen, Ch., 1986, "Chaos in a Railway Bogie", Acta Mechanica, Vo1. 61, pp. 89-107.

Knudsen, C., Feldberg, R., and Jaschinski, A., 1991,

"Non-1inear Dynamic Phenomena in the Behaviour of a Railway Wheelset Model", Nonlinear Dynamics, Vol. 2, pp. 389-404.

Knudsen, C., Feldberg, R., and True, H., 1992, "Bi-

furcations and Chaos in a Model of a rolling Raitway

Wheelset", Phil. Trans. R. Soc. Lond. A, in print.

Meijaard, J.P. 1991, "Dynamics of Mechanical Systems; Algorithms for a Numerical Investigation of the Behaviour of Non-1inear Discrete Models", Doctoral Thesis, Technische Universiteit Delft, The Netherlands.

True, H., 1992, "Railway Vehicle Chaos and Asymmetric Hunting", Proceedings, 11 th IAVSD-Symposium, G. Sauvage, ed., Swets \& Zeitlinger inc. Amsterdam, Lisse, Rockland MA, Berwyn PA, in print. 